\title{
Enhanced apoptosis of ovarian cancer cells via nanocarrier-mediated codelivery of siRNA and doxorubicin
}

This article was published in the following Dove Press journal:

International Journal of Nanomedicine

17 July 2012

Number of times this article has been viewed

\author{
Seyin Zou ${ }^{1,3, \dagger}$ \\ Nuo Cao ${ }^{1, \dagger}$ \\ Du Cheng ${ }^{2}$ \\ Rongqin Zheng ${ }^{4}$ \\ Jin Wang ${ }^{4}$ \\ Kangshun $\mathrm{Zhu}^{4}$ \\ Xintao Shuai ${ }^{1,2}$ \\ 'Center of Biomedical Engineering, \\ Zhongshan School of Medicine, \\ 2PCFM Lab of Ministry of Education, \\ School of Chemistry and Chemical \\ Engineering, ${ }^{3}$ Department of \\ Laboratory Medicine, The Third \\ Affiliated Hospital, Guangzhou \\ Medical University, ${ }^{4}$ The Third \\ Affiliated Hospital, Sun Yat-Sen \\ University, Guangzhou, China \\ †These authors contributed equally \\ to this work
}

Correspondence: Kangshun Zhu The Third Affiliated Hospital, Sun Yat-Sen University, Guangzhou 510630, China

Tel +862085252066

Email zhksh0I0@I63.com

Xintao Shuai

Center of Biomedical Engineering, Zhongshan School of Medicine, Sun YatSen University, Guangzhou 510080, China Tel +862084 I। 0365

Fax +86 20 84II 2245

Email shuaixt@mail.sysu.edu.cn
Abstract: A folate conjugated ternary copolymer, FA-PEG-PEI-PCL, of poly(ethylene glycol) (PEG), poly(ethylene imine) (PEI), and poly( $\varepsilon$-caprolactone) (PCL) was synthesized. The copolymer self-assembled into cationic micelles capable of co-delivering siRNA and the anticancer drug doxorubicin (DOX). This dual functional nanocarrier demonstrated low cytotoxicity and high performance in drug/siRNA delivery. Upon the codelivery of siRNA, targeting the Bcl-2 gene, and DOX, using the folate-targeted nanocarrier, DOX-induced apoptosis in the skov-3 cells overexpressing folate receptor was significantly enhanced through a mechanism of downregulating the antiapoptotic protein $\mathrm{Bcl}-2$, while simultaneously upregulating the proapoptotic protein Bax. This work suggested that the combination of Bcl-2 siRNA and DOX therapies is feasible, based on our dual functional nanocarrier, which set up a good basis for a future in vivo test.

Keywords: codelivery, gene silencing, chemotherapy, apoptosis, tumor targeting

\section{Introduction}

In the United States, ovarian cancer is the fifth most prevalent cancer among women, with a lifetime risk of $1.4 \%-1.8 \%$. The disease stage is the primary factor determining the survival rate of patients, and it has been reported that the median 5-year survival rates of stage I, II, III, and IV ovarian cancer patients are approximately $93 \%, 70 \%$, $37 \%$, and $25 \%$, respectively. ${ }^{1,2}$ In many cases, chemotherapy becomes the only effective option for ovarian cancer treatment. ${ }^{3}$ Doxorubicin (DOX) has been widely used as a small molecular chemotherapeutic drug to treat various cancers in the clinic, including ovarian cancer. ${ }^{46}$ However, drug resistance may occur in tumor cells, which reduces drug potency in inducing the apoptosis of cancer cells and severely restricts its full use in clinic. ${ }^{5,7,8}$ Previous research studies have confirmed that cancer cells could develop various mechanisms to reduce the anticancer efficacies of DOX, ${ }^{9-12}$ including the upexpression of apoptotic inhibitor Bcl- $2,{ }^{13}$ which leads to the decreased sensitivity of tumor cells to DOX.

It is well established that $\mathrm{Bcl}-2$ can protect tumor cells against most cytotoxic agents. For example, overexpression of Bcl-2 was shown to block DOX-induced apoptosis in an earlier study. ${ }^{14}$ Therefore, downregulation of Bcl-2 gene expression by siRNA targeting Bcl-2 mRNA may sensitize cancer cells, such as MCF-7 and hepatic cancer cells, to DOX. ${ }^{15,16}$ On the other hand, it has been proven that nano-based chemotherapeutics improve the efficacy of drugs, lessen toxicity to normal tissue, and improve patient compliance rate. ${ }^{17} \mathrm{~A}$ recent advance in nanomedicine for cancer 
therapy is the development of multifunctional nanocarriers, which may jointly deliver chemotherapeutic drugs and genes or siRNA. ${ }^{18,19}$ So far, co-delivery of anticancer drugs and siRNA has shown great potential in improving the potency of anticancer drugs, both in vitro and in vivo. ${ }^{20,21}$ More importantly, the synergistic anticancer effects of siRNA targeting drug-resistance genes and chemotherapeutic drugs may be achieved. Upon functionalization of the nanocarriers with molecular-targeting ligands, tumor cell-specific delivery of both therapeutic agents may be realized simultaneously. Previous studies have shown that the expression of folate receptors was obviously upregulated in many epithelial tumors, including ovarian. Therefore, delivery of nanocarriers into these cells can be enhanced using the folate-directed targeting strategy. ${ }^{16}$

Herein, we developed a folate-targeted, multifunctional nanocarrier for codelivering DOX and siRNA targeting the Bcl-2 gene (Bcl-2 siRNA) into ovarian cancer cells overexpressing receptors for folic acid (FA), in the hope of suppressing drug resistance, thereby enhancing apoptosis of cancer cells in DOX treatment. The nanocarrier was prepared based on a triblock copolymer (PEG-PEI-PCL) of poly(ethylene glycol) (PEG), poly(ethylene imine) (PEI), and poly( $\varepsilon$-caprolactone) (PCL). Unlike the triblock copolymer PEG-PEI-PCL used previously for gene delivery, which possessed a mid-block PCL, ${ }^{22}$ the copolymer synthesized in the present study possesses a mid-block PEI. In addition, linear PEI with low molecular weight, rather than hyperbranched PEI with high molecular weight, was used as the cationic building block, which is in favor of reducing cationic toxicity of the vector. On the other hand, complex based on PEG-PEI-PCL is believed to possess a better stability than that based on a hierarchical multilayer assembly, in which PEG coating of polyplex was achieved upon electrostatic interaction, rather than covalent linkage. ${ }^{16}$

\section{Materials and methods Materials}

The diblock copolymer of linear PEI and poly( $\varepsilon$-caprolactone) $($ PPEI-PCL $)\left(M_{\mathrm{n}-\mathrm{PCL}}=1.6 \mathrm{kDa}, M_{\mathrm{n}-\mathrm{PEI}}=2 \mathrm{kDa}\right.$, $)$ was synthesized as reported recently. ${ }^{16}$ Skov-3 human ovarian cancer cell line overexpressing surface receptors for FA was obtained from the Cell Bank of Shanghai Institutes for Biological Sciences (Shanghai, China). Two siRNA duplexes, designed to target Bcl-2 gene using algorithms from public software, were provided by Genpharm (Shanghai, China). They are the 21st long double-stranded RNA oligos with dTdT overhang at the $3^{\prime}$ end, with sequences as follows: Bcl-2-1: (sense) 5'-UGUGGAUGACUGAGUACCUGAdTdT-3', (antisense) 5'-UCAGGUACUCAGUCAUCCACAdTdT-3'; Bcl-2-2: (sense) 5'-GUACAUCCAUUAUAAGCUGUCd TdT-3', (antisense) 5'-GACAGCUUAUAAUGGAUGUA CdTdT-3'.

Two scrambled siRNA (SCR) duplexes which were prepared as control have sequences as follows: Bcl2-S1: (sense) 5'-GGGUAAGUGUCCUACUGAAGUdTdT -3', (antisense) 5'-ACUUCAGUAGGACACUUACCCdTd T-3'; Bcl-2-S2 (sense) 5'-GCUUGAAAUCUAUGCACUC AUdTdT-3', (antisense) 5'-AUGAGUGCAUAGAUUUCA AGCdTdT-3'.

The siRNA cocktail containing Bcl-2-1 and Bcl-2-2 (equal molar ratio) was named as Bcl-2 siRNA. The control SCR cocktail was prepared by the same method. The FITClabeled scrambled siRNA was obtained from Invitrogen (Carlsbad, CA).

\section{Synthesis of FA-PEG-PEI-PCL}

Synthesis of hydroxyl- and folate-capped poly(ethylene glycol) (FA-PEG-OH)

$\alpha$-Hydroxy- $\omega$-amino-poly(ethylene glycol) (HO-PEG$\left.\mathrm{NH}_{2}\right)\left(M_{\mathrm{n}}=4 \mathrm{kDa}\right)$ was prepared according to a previous report. ${ }^{23}$ To conjugate folate to $\mathrm{HO}-\mathrm{PEG}-\mathrm{NH}_{2}$, folic acid ( $1 \mathrm{mmol})$ was dissolved in anhydrous DMSO $(5 \mathrm{~mL})$. N-hydroxysuccinimide (NHS, 2 mmol) and dicyclohexylcarbodiimide (DCC, $2 \mathrm{mmol}$ ) were added, and the mixture was stirred for 12 hours. The solution was mixed with a DMSO solution $(5 \mathrm{~mL})$ of HO-PEG-NH $2(0.5 \mathrm{mmol})$, and triethylamine (TEA) was added to adjust the solution $\mathrm{pH}$ to 8.0. The mixture was then stirred for 24 hours, filtrated, dialyzed against deionized water (MWCO: $1 \mathrm{kDa}$ ), and lyophilized to obtain a yellowish powdery product.

\section{Synthesis of carboxyl- and folate-capped poly(ethylene glycol) (FA-PEG-COOH)}

FA-PEG-OH was converted into FA-PEG-COOH by reaction with succinic anhydride (SA). Vacuum-dried FA-PEG-OH and SA (molar ratio: 1:10) were dissolved in $20 \mathrm{~mL}$ anhydrous chloroform and refluxed at $70^{\circ} \mathrm{C}$ for 48 hours. After the solution was cooled down, it was concentrated to $5 \mathrm{~mL}$ and filtered to remove the crystallized SA. The chloroform solution was precipitated into cold diethyl ether, and then filtered to a white powdery product. To ensure the complete removal of SA, the polymer was redissolved in $20 \mathrm{~mL}$ deionized water and dialyzed against water for 2 days. Finally, the polymer solution was freeze-dried to yield pure FA-PEG-COOH. 


\section{Synthesis of folate capped triblock copolymer}

of poly(ethylene glycol), poly(ethylene imine) and poly ( $\varepsilon$-caprolactone) (FA-PEG-PEI-PCL)

First, vacuum-dried FA-PEG-COOH $(0.25 \mathrm{mmol})$ was activated with NHS $(0.5 \mathrm{mmol})$ for 24 hours in dry dichloromethane $(20 \mathrm{~mL})$ containing dicyclohexylcarbodiimide $(0.5 \mathrm{mmol})$ as a catalyst. The precipitated 1,3-dicyclohexylurea (DCU) was removed by filtration through a $0.45 \mu \mathrm{m}$ membrane. The filtrate was added to cold diethyl ether, filtered, washed with diethyl ether and isopropyl alcohol, and dried under vacuum at room temperature to obtain the NHS-activated powdery product (FA-PEG-NHS).

In the second step, IPEI-PCL $(0.25 \mathrm{mmol})$ and the FAPEG-NHS $(0.25 \mathrm{mmol})$ were dissolved in DMSO $(10 \mathrm{~mL})$ and magnetically stirred for 24 hours at room temperature. The mixture was added to distilled water and purified by membrane dialyses (MWCO: $8000 \mathrm{Da}$ ) against water for 3 days. It then was lyophilized to obtain the folate-targeted triblock copolymer FA-PEG-PEI-PCL $\left(M_{\mathrm{n}}=7.6 \mathrm{kDa}\right.$, calculated by ${ }^{1} \mathrm{H}$ NMR). In the synthesis, nontargeting PEG-PEI-PCL was synthesized by the same approach, using the NHS/DCC chemistry, in which Allyl-PEG-OH was converted to Allyl-PEG-COOH, activated with NHS, and then conjugated to PEI-PCL.

\section{Preparation of DOX-loaded micelles and determination of DOX-loading contents}

DOX-loaded and blank nontargeting PEG-PEI-PCL micelles were denoted as D-NPPP and B-NPPP, respectively. DOXloaded and blank targeting FA-PEG-PEI-PCL micelles were denoted as D-FPPP and B-FPPP, respectively. The micelles were prepared as follows: $10 \mathrm{mg}$ of polymer (ie, FA-PEG-PEI-PCL or PEG-PEI-PCL), and $2 \mathrm{mg}$ of deprotonated DOX were codissolved in $2 \mathrm{~mL}$ of chloroform. Afterwards, the solution was added, dropwise, to pure water $(20 \mathrm{~mL})$, under ultrasonic agitation, using a Type 60 Sonic Dismembrator (Fisher Scientific, Fairlawn, NJ) at a power level of 30 . The organic solvent chloroform was then completely removed by vacuum distillation, using a rotary evaporator, to allow micelle formation. The micelle solution was concentrated and washed three times using a centrifugal filter device (MW cut-off: 100,000 Da; Millipore, Billerica, $\mathrm{MA}$ ) to remove free DOX dissolved in the micelle solution, and then filtered with a syringe filter (pore size: $0.45 \mu \mathrm{m}$ ) to eliminate large polymer or DOX aggregates.

The DOX-loading content, which was defined as the weight percentage of DOX in micelle, was quantified using UV-vis analysis on a Unico UV-2000 UV-vis spectrophotometer
(Unico Instruments, Shanghai, China), as follows: DOXloaded micelle solutions were lyophilized to yield the solid samples, after which the completely dried micelle samples were weighed and then redissolved in a mixture of chloroform and DMSO $(1: 1, \mathrm{v} / \mathrm{v})$. The DOX absorbance at $482.5 \mathrm{~nm}$ was measured to determine DOX content in the solution, using a pre-established calibration curve, which was then converted to the DOX-loading content of the micelles.

\section{Preparation of DOX- and siRNA-loaded nanocomplexes}

A predetermined (eg, $0.1 \mu \mathrm{g}$ ) amount of Bcl-2 siRNA or scrambled siRNA (SCR) was added to a vial containing the cationic micelle solution. Different micelle concentrations were used in the preparation, according to the designed experimental N/P ratios. The mixture was vortexed for 15 seconds and then kept still at room temperature for 30 minutes. A series of folate targeted or nontargeting siRNA-DOX-loaded and DOX-free complexes, (ie, D-FPPP/ Bcl-2, B-FPPP/Bcl-2, D-NPPP/Bcl-2, B-NPPP/Bcl-2, D-FPPP/SCR, B-FPPP/SCR, D-NPPP/SCR, and B-NPPP/ $\mathrm{SCR}$ ), were formed at predetermined N/P ratios. Complexes containing FITC-labeled SCR (D-PPP/FITC) were prepared in the same way and used in the cell uptake study.

\section{Characterization of nanoparticles}

The hydrodynamic sizes and zeta potentials of the prepared cationic micelles and siRNA complexes were determined by dynamic light scattering (DLS). Measurements were performed at $25^{\circ} \mathrm{C}$ on 90 Plus/BI-MAS equipment (Brookhaven Instruments Corporation, Holtsville, NY). For the $\zeta$-potential measurement, a standard electrophoresis minicell from Brookhaven was used. The data for particle size and $\zeta$-potential were collected on an autocorrelator with a detection angle of scattered light at $90^{\circ}$ and $15^{\circ}$, respectively. For each sample, data obtained from five measurements were averaged to yield the mean particle size and $\zeta$-potential. Samples for scanning electron microscopy (SEM; Quanta 400F; FEI, Eindhoven, The Netherlands) analysis were prepared by drying a dispersion of solution on a clean glass slide for 24 hours in a desiccator. A thin layer of gold was sputter-coated on the samples for charge dissipation during SEM imaging.

\section{Determination of siRNA complexation by gel retardation assay}

In order to assess the siRNA complexation ability of the delivery agents, gel electrophoresis was performed 
on a Bio-Rad Sub-Cell electrophoresis cell (Bio-Rad Laboratories, Richmond, CA), and images were obtained on a DNR Bio-Imaging Systems (DNR Bio-Imaging Systems Ltd, Jerusalem, Israel). Complex formation was induced at various $\mathrm{N} / \mathrm{P}$ ratios, from 0 to 5 , in $0.9 \%$ sodium chloride solution. The complexes were loaded onto the $1 \%$ agarose gels with ethidium bromide $(0.5 \mathrm{mg} / \mathrm{mL})$ and run with TBE buffer (4.5 mM of Tris base, $1 \mathrm{mM}$ of sodium EDTA, $4.5 \mathrm{mM}$ of boric acid, $\mathrm{pH}=8.3$ ) at $100 \mathrm{~V}$ for 45 minutes. Retardation of siRNA mobility was revealed by irradiation with UV light.

\section{Cell transfection}

Human ovarian cancer skov-3 cells were routinely cultured in RPMI-1640 media supplemented with 10\% fetal bovine serum (FBS; Gibco-BRL, Carlsbad, CA) at $37^{\circ} \mathrm{C}$ in a humidified atmosphere of $5 \% \mathrm{CO}_{2}$. The skov-3 cells were seeded in 24-well plates at a density of $1 \times 10^{4}$ cells per well and incubated overnight in $400 \mu \mathrm{L}$ of RPMI-1640 containing $10 \%$ FBS. The medium was changed to $400 \mu \mathrm{L}$ of FA-deficient and FBS-free RPMI-1640, and then the cells were incubated at $37^{\circ} \mathrm{C}$ for 4 hours. Subsequently, $40 \mu \mathrm{L}$ of complex solution was added to each well at a siRNA concentration of $50 \mathrm{nM}$, and then the cells were incubated for another 4 hours. After the medium was replaced with RPMI-1640 containing FA and FBS, the cells were further incubated, for at least 48 hours, and then harvested for real-time PCR, enzyme-linked immunosorbent assay (ELISA) analyses, etc.

\section{Cell viability assay}

The inhibition of tumor cell growth was analyzed using the MTT assay. All experiments were conducted in triplicate. Skov-3 cells were seeded at a density of $1 \times 10^{3}$ cells/well in 96-well plates, and $150 \mu \mathrm{L}$ of RPMI-1640, supplemented with $10 \%$ FBS, was added to each well, and the cell was incubated overnight at $37^{\circ} \mathrm{C}$. After the culture medium was replaced with FA-deficient and serum-free RPMI-1640, the cells were incubated for 48 hours in the presence of nanocomplexes at a siRNA concentration of $20 \mathrm{nM}$ per well. One hundred microliters of serum-free growth medium and $10 \mu \mathrm{L}$ of MTT solution $(5 \mathrm{mg} / \mathrm{mL})$ were added into each well, and the cells were further incubated for 4 hours. After the supernatant in the wells was discarded, $100 \mu \mathrm{L}$ of DMSO was added to dissolve the substrate. After gentle agitation, the absorbance at $570 \mathrm{~nm}$ was recorded on a Tecan Infinite F200 Multimode plate reader. Cell viability was estimated as a percentage of the value of the untreated control cells.

\section{Real time-PCR assay for mRNA level of $\mathrm{Bcl}-2$ gene}

Total RNA was extracted from the cells using the TRIzol LS reagents (Invitrogen). The first strand cDNA was synthesized using cDNA superscript preamplification system (TaKaRa Biotechnology, Tokyo, Japan) with oligo(dT) as a primer. To assess the mRNA expression of Bcl-2, a quantitative realtime PCR was performed, using a SYBR ${ }^{\circledR}$ Premix ExTaqTM Kit (TaKaRa Biotechnology). The forward and reverse primers targeting the Bcl-2 sequence were $5^{\prime}$-GTGGTGGAGGAGCTCTTCAG-3' and 3'-CTACCCAGCCTCCGTTATCCT- $5^{\prime}$, respectively. The mRNA level of $\beta$-actin gene was also measured as an internal normalization standard. The forward primer was 5'-CCATCATGAAGTGTGACGTGG-3', and the reverse primer was $5^{\prime}$-GTCCGCCTAGAAGCATTTGCG-3'. The experiments were carried out on a StepOnePlus RT-PCR System (Applied Biosystems, Foster City, CA). Each amplified sample was analyzed for homogeneity, using dissociation curve analysis. After denaturation at $95^{\circ} \mathrm{C}$ for 5 minutes, 40 cycles were performed at $95^{\circ} \mathrm{C}$ for 30 seconds, $60^{\circ} \mathrm{C}$ for 30 seconds, and $72^{\circ} \mathrm{C}$ for 30 seconds. Relative quantification was calculated using the stand curve method (Bcl-2 copies/ $\beta$-actin copies). A standard curve was generated for each primer, upon which gene expression levels were normalized. Finally, a ratio was calculated by comparing the normalized gene expression values in treated versus untreated control for each cell sample.

\section{Flow cytometry analysis}

After incubation, as previously described, the cells were trypsinized and collected, washed with phosphate-buffered saline (PBS), and then resuspended in $0.25 \mathrm{~mL}$ of PBS. Samples were analyzed by flow cytometry on a FACSCalibur (Beckton Dickinson, San Jose, CA), using a $488 \mathrm{~nm}$ laser for FITC and DOX excitation; $2 \times 10^{4}$ cells were analyzed in each group. The fluorescence from DOX was collected through a $575 \mathrm{~nm}$ filter, and the green emission of FITC was measured with a $525 \mathrm{~nm}$ filter. Normally cultured cells without nanocomplex transfection were used as a control for background calibration.

\section{Terminal deoxynucleotidyltransferase- mediated UTP end labeling (TUNEL) assay}

The cells were seeded at a density of $1 \times 10^{4}$ per well in 24-well plates and incubated overnight at $37^{\circ} \mathrm{C}$. The nanocomplexes were added to incubate the cells for 96 hours. A TUNEL assay 
was performed, using an In Situ Cell Apoptosis Detection Kit I (POD), according to the manufacturer's protocol (Boster, Wuhan, China). In brief, after $100 \mu \mathrm{L}$ of $4 \%$ paraformaldehyde was added to each well, the cells were incubated for 30 minutes at room temperature and then washed with deionized $\mathrm{H}_{2} \mathrm{O}$ twice and PBS twice. Then, $3 \% \mathrm{H}_{2} \mathrm{O}_{2}$ aqueous solution was added to inactivate endogenous peroxidase at room temperature for 10 minutes, after which the cells were washed with PBS and treated with labeling buffer containing terminal deoxynucleotidyl transferase (TdT Enzyme) and DIG-dUTP at $37^{\circ} \mathrm{C}$ for 2 hours, and washed again with PBS. After the blocking reagent was added at $37^{\circ} \mathrm{C}$ for 30 minutes, the cells were washed with PBS, and the exposed $3^{\prime}-\mathrm{OH}$ ends of the breakage DNA fragment in the apoptotic cells were labeled with biotin-labeled anti DIG at $37^{\circ} \mathrm{C}$ for 30 minutes. The cells were incubated at room temperature for 30 minutes with streptavidin-horseradish peroxidase conjugate. The diaminobenzidine reacted with the labeled sample to generate an insoluble brown DAB signal, while bluegreen to greenish tan signified nonapoptotic cells.

\section{Enzyme-linked immunosorbent assay (ELISA) and caspase-3 activity analysis}

The levels of protein expression of Bcl-2/Bax and activity of caspase- 3 were evaluated. The cells were seeded at a density of $1 \times 10^{5}$ per well in 6-well plates and incubated overnight at $37^{\circ} \mathrm{C}$, followed by the addition of nanocomplexes. After a 72-hour cell incubation, total protein was extracted from the cells, using lysis buffer-containing protease inhibitor cocktail set III and phosphatase inhibitor cocktail set I (Calbiochem, EMD Biosciences, San Diego, CA). The protein concentrations of all the samples were determined with a Bicinchoninic Acid Protein Assay Kit (Invitrogen). The levels of Bcl-2 and Bax proteins were quantified using the Human Bcl2/Bax ELISA Kit, according to the manufacturer's instructions (Quantikine Human bcl2/bax; R\&D Systems, Milan, Italy). Caspase-3 activity was quantitatively measured using a Caspase-3 Colorimetric Assay Kit according to the manufacturer's instructions (Keygene, Nanjing, China). In brief, the assay is based on measuring the amount of the chromophore p-nitroaniline (pNA) liberated from the labeled substrate DEVD-pNA at $405 \mathrm{~nm}$. Caspase-3 activities are expressed as fold increases over the nontreated cell control. ${ }^{24}$

\section{Statistical analysis}

Statistical analysis was performed using SPSS software (version 17.0; SPSS Inc, Chicago, IL). Results are reported as mean $\pm \mathrm{SD}$. Statistical significance among groups was determined by one-way analysis of variance (ANOVA) with
Bonferroni correction. Probability values of $P<0.05$ were considered significant.

\section{Results \\ Synthesis and characterization of block copolymers}

The ternary copolymers were synthesized via multistep reactions, as shown in Figure 1. The chemical structures of the copolymers were confirmed by the ${ }^{1} \mathrm{H}$ NMR analysis, as shown in Figure 2. DOX was turned hydrophobic upon deprotonation and then encapsulated in the hydrophobic PCL core of the micelles (Figure 3). The folate-targeted micelles and nontargeting ones showed little difference in the DOX loading content at any drug:polymer feed ratio applied for the micelle preparation. The highest DOX-loading contents obtained in our experiments were $4.56 \%$ for the FA-PEG-PEI-PCL micelles (D-FPPP) and 5.14\% for the PEG-PEI-PCL micelles (D-NPPP), both of which were achieved at a drug:polymer feed ratio of 1:10 and used for the biological studies.

\section{Particle size and zeta potential measurements}

As shown in Figure 4, because there are no differences in block lengths or structures between FA-PEG-PEI-PCL and PEG-PEI-PCL, their particle sizes and zeta potentials changed similarly, along with increasing N/P ratios for siRNA complexation. At any of the N/P ratios studied in the experiment, both copolymers showed fairly close data in both particle size and zeta potential. For example, at N/P 5, the particle sizes were $191 \mathrm{~nm}$ and $188 \mathrm{~nm}$ and the zeta potentials were $+6.51 \mathrm{mV}$ and $+5.32 \mathrm{mV}$ for D-FPPP/Bcl-2 and D-NPPP/Bcl-2, respectively. Higher N/P values resulted

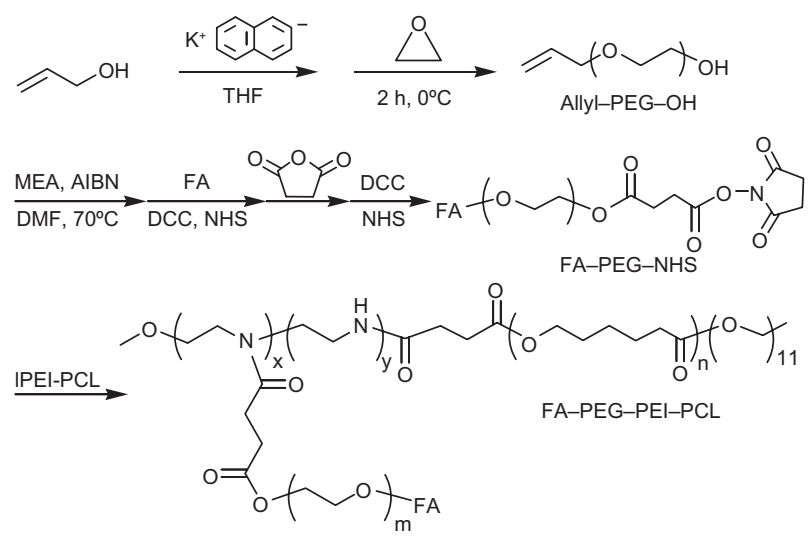

Figure I Synthesis of folate-conjugated triblock copolymer FA-PEG-PEI-PCL. Abbreviations: FA-PEG-NHS, folate-poly(ethylene glycol)-N-hydroxysuccinimide; IPEI-PCL, linear poly(ethylene imine)-poly( $\varepsilon$-caprolactone); FA-PEG-PEI-PCL, folate-poly(ethylene glycol)-poly(ethylene imine)-poly( $\varepsilon$-caprolactone). 

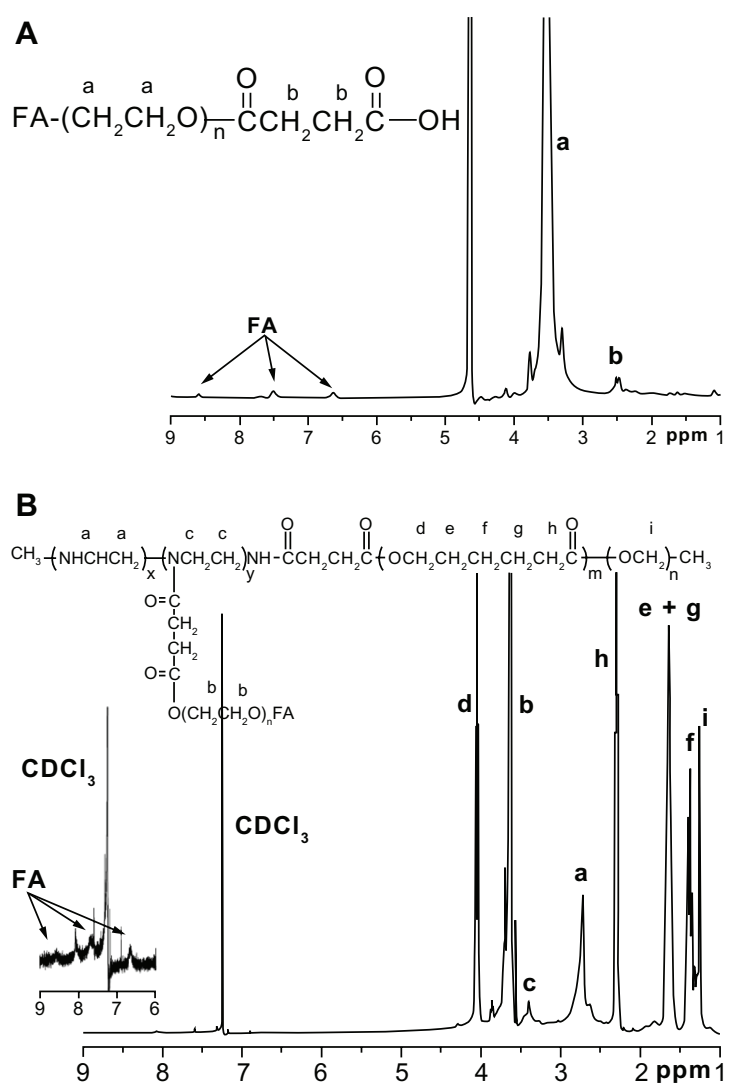

Figure 2 ' $\mathrm{H}$ NMR spectra $(300 \mathrm{MHz})$ of (A) FA-PEG-COOH in $\mathrm{D}_{2} \mathrm{O}$ and (B) FA-PEG-PEI-PCL in $\mathrm{CDCl}_{3}$.

Abbreviations: FA-PEG-COOH, folate-poly(ethylene glycol)-COOH; FA-PEGPEI-PCL,folate-poly(ethylene glycol)-poly(ethylene imine)-poly(E-caprolactone).

in higher positive charges, but smaller particle sizes of the nanocomplexes for both the FA-PEG-PEI-PCL and PEGPEI-PCL micelles. Furthermore, over N/P 30, the particle zeta potentials kept increasing, whereas the particle size

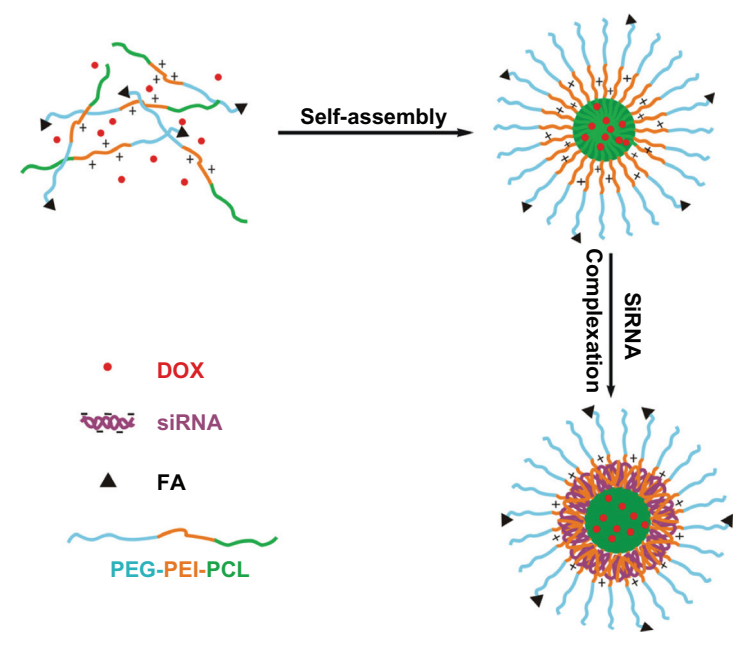

Figure 3 Preparation of DOX and siRNA coencapsulated nanocomplexes with folate receptor-targeting function.

Abbreviations: DOX, doxorubicin; FA, folate; siRNA, small interference RNA; PEG-PEI-PCL, poly(ethylene glycol)-poly(ethylene imine)-poly(E-caprolactone).
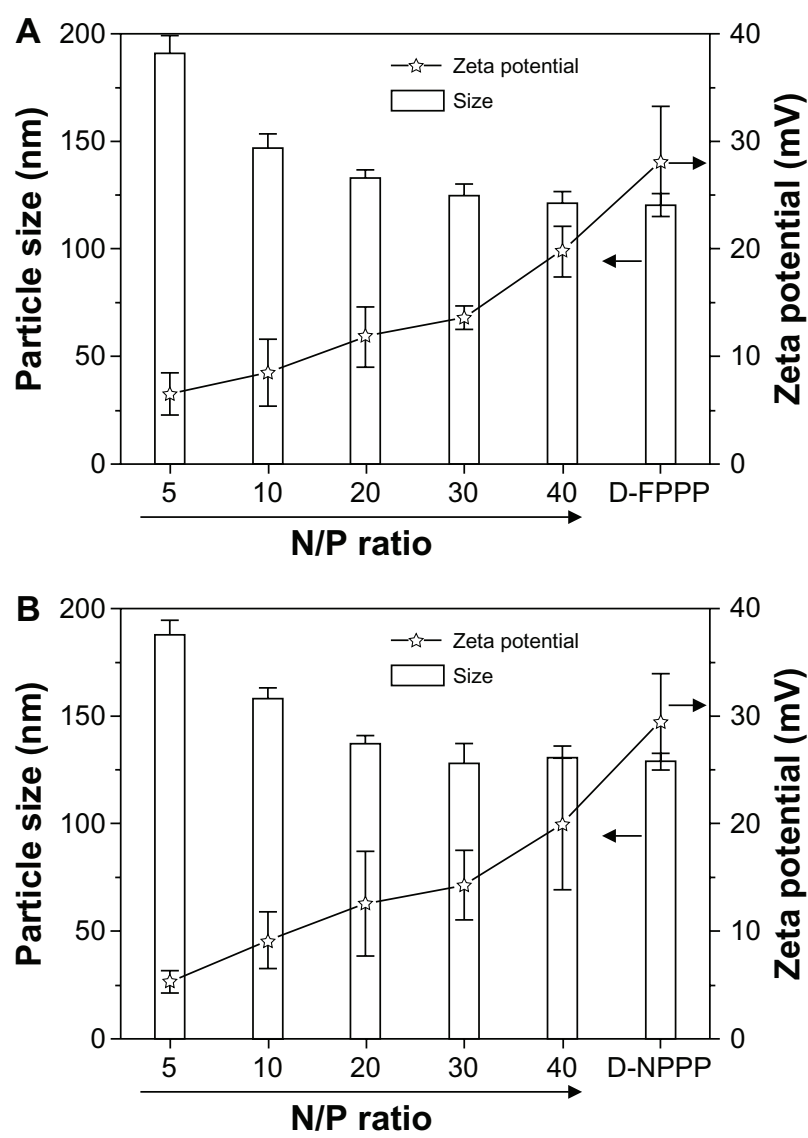

Figure 4 Particle sizes and zeta potentials of siRNA and DOX-loaded nanocomplexes (A) D-FPPP/Bcl-2 and (B) D-NPPP/Bcl-2 formed at different N/P ratios $(n=5)$, as determined by DLS measurements.

Note: DOX loading contents: $4.56 \%$ in D-FPPP and $5.14 \%$ in D-NPPP.

Abbreviations: DOX, doxorubicin; D-FPPP, DOX-loaded folate-poly(ethylene glycol)-poly(ethylene imine)-poly( $\varepsilon$-caprolactone) micelle; D-NPPP, DOX-loaded nontargeted poly(ethylene glycol)-poly(ethylene imine)-poly( $\varepsilon$-caprolactone) micelle; DLS, dynamic light scattering; D-FPPP/Bcl-2, Bcl-2 siRNA and DOX loaded folate-poly(ethylene glycol)-poly(ethylene imine)-poly( $\varepsilon$-caprolactone) micelle; D-NPPP/Bcl-2, Bcl-2 siRNA and DOX loaded nontargeted poly(ethylene glycol)poly(ethylene imine)-poly( $\varepsilon$-caprolactone) micelle.

remained almost constant, along with further increasing the $\mathrm{N} / \mathrm{P}$ ratios.

\section{Gel retardation assay}

Agarose gel electrophoresis was conducted to confirm the siRNA complexation ability of the folate-targeted and nontargeting DOX-loaded FA-PEG-PEI-PCL and PEG-PEI-PCL micelles (ie, the D-FPPP and D-NPPP micelles). Complexation of nucleic acids with cationic polymers is driven by electrostatic neutralization, during which siRNA or pDNA partially or completely loses negative charge and, consequently, loses mobility in the electric field. ${ }^{25,26}$ Therefore, siRNA mobility in gel electrophoresis can be checked as a measure of the polymer ability to complex siRNA. As shown in Figure 5, siRNA motion for both D-FPPP/siRNA and D-NPPP/siRNA was completely retarded at almost the same N/P ratio, around 5, 


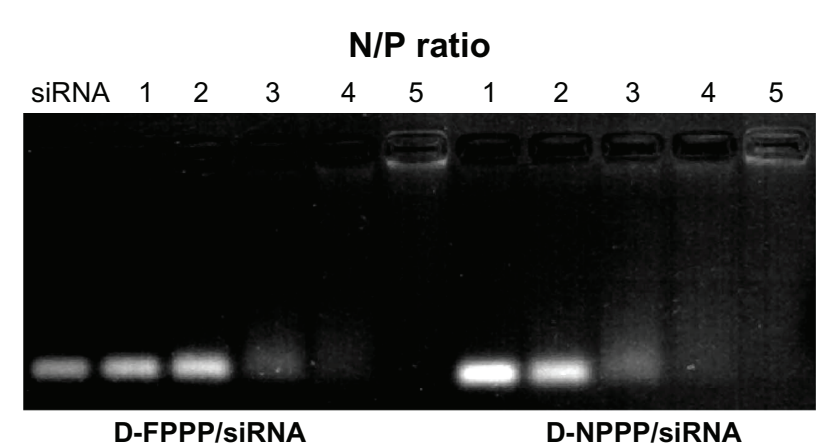

Figure 5 Electrophoretic mobility of siRNA in agarose gel after complexing with DOX-loaded FA-PEG-PEI-PCL micelle (D-FPPP) and DOX-loaded PEG-PEI-PCL micelle (D-NPPP) at various N/P ratios.

Abbreviations: DOX, doxorubicin; siRNA, small interference RNA; D-FPPP, DOX loaded folate-poly(ethylene glycol)-poly(ethylene imine)-poly(E-caprolactone) micelle; D-NPPP, DOX loaded nontargeted poly(ethylene glycol)-poly(ethylene imine)-poly( $\varepsilon$-caprolactone) micelle.

indicating full neutralization of the siRNA negative charge. ${ }^{16}$ The result also implied that folate molecules in the DOXloaded micelles have little effect on the siRNA complexation. Scanning electron microscopy (SEM) observations showed that siRNA complexation (N/P=5) did not affect the nanocomplex morphology, but it increased the particle size (Figure 6), which is consistent with the data shown in Figure 4.

Small size and weak positive charge are preferable in terms of easy cell uptake of nanoparticles. Besides, low positive charge may enhance the stability of nanoparticles in vivo, because a nanoparticle surface with a high positive charge may interact easily with negatively charged biosubstances, such as proteins. Therefore, the DOX and siRNA nanocomplexes prepared at N/P 30 showed the smallest particle sizes, whereas moderate positive charges were chosen for the following biological experiments.

\section{Cell uptake of nanocomplexes}

Folate receptor (FA)-mediated cell uptake of the nanocomplex FA-DPPP/siRNA (N/P 30; DOX loading content
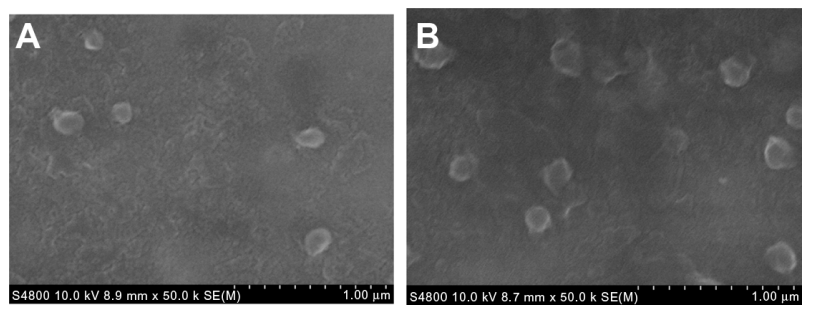

Figure 6 Scanning electron microscopy (SEM) images of the (A) DOX-loaded micelle D-NPPP and (B) DOX-SCR-loaded nanocomplex D-NPPP/SCR (N/P = 30). Abbreviations: DOX, doxorubicin; D-NPPP, DOX loaded nontargeted poly(ethylene glycol)-poly(ethylene imine)-poly(e-caprolactone) micelle; D-NPPP/ SCR, scrambled siRNA and DOX loaded nontargeted poly(ethylene glycol)poly(ethylene imine)-poly( $\varepsilon$-caprolactone) micelle.
$4.56 \%$ ) was evaluated using flow cytometry and laser confocal microscopy in FR-enriched human ovarian cancer skov-3 cells. To evaluate the internalization of siRNA into cells, FITC-labeled scrambled siRNA (SCR-FITC) was used. As shown in Figure 7, cells incubated with D-FPPP/ FITC showed much stronger DOX (red) and siRNA (green) fluorescence in comparison with cells incubated with the nontargeting D-NPPP/FITC. Quantitative flow cytometric analysis showed that the percentage of FITC-DOX-positive cells increased significantly ( $85.7 \%$ vs $43.9 \%)$ when the cells were incubated with D-FPPP/FITC, compared to D-NPPP/FITC. Apparently, DOX and siRNA were transferred into cells much more efficiently using the targeting nanocomplex than the nontargeting one. Moreover, DOX and siRNA showed identical intracellular distribution patterns, mainly in cytoplasm, indicating the co-delivery of the two cargoes into the skov-3 cells. Red and green fluorescence inside cells transfected with D-FPPP/FITC overlapped to exhibit yellow stains in the merged image. The presence of excessive free folate $(1 \mathrm{mg} / \mathrm{L})$ in the culture media effectively lowered the cell uptake efficiency to the basic level for the nontargeting D-NPPP/FITC (47.5\% vs $43.9 \%$ ), which implied that the enhanced cell uptake of D-FPPP/FITC was due to the FR-mediated endocytosis. Codelivery of DOX and siRNA into the same cells is especially important, as Bcl-2 siRNA was used jointly to improve cell susceptibility to DOX-inducible apoptosis (ie, drug potency).

\section{Downregulation of $\mathrm{Bcl}-2$ gene expression}

In this study, a siRNA cocktail comprised of two siRNAs (1:1 mixture) targeting the Bcl-2 gene was used. Suppression on the expression of Bcl-2 gene in skov-3 cells at the mRNA level was first assessed by real time-PCR assay. When nontherapeutic SCR was encapsulated in the nanocomplexes, DOX-loaded nanocomplexes showed much higher levels of Bcl-2 mRNA in the skov-3 cells than the DOX-free ones (Figure 8, two pairs on the right side of figure), which indicates that DOX treatment induced up-regulation of the drug-resistant Bcl-2 gene. However, cells treated with nanocomplexes containing Bcl-2 siRNA all showed fairly low levels of Bcl-2 mRNA, regardless of whether DOX was codelivered or not, and folate targeting further enhanced such a suppression effect (Figure 8, two pairs on the left side of figure). Apparently, DOX treatment-inducible Bcl-2 gene upregulation in skov-3 cells was effectively suppressed by the codelivered Bcl-2 siRNA using our dual-functional nanocarriers for siRNA and DOX. 

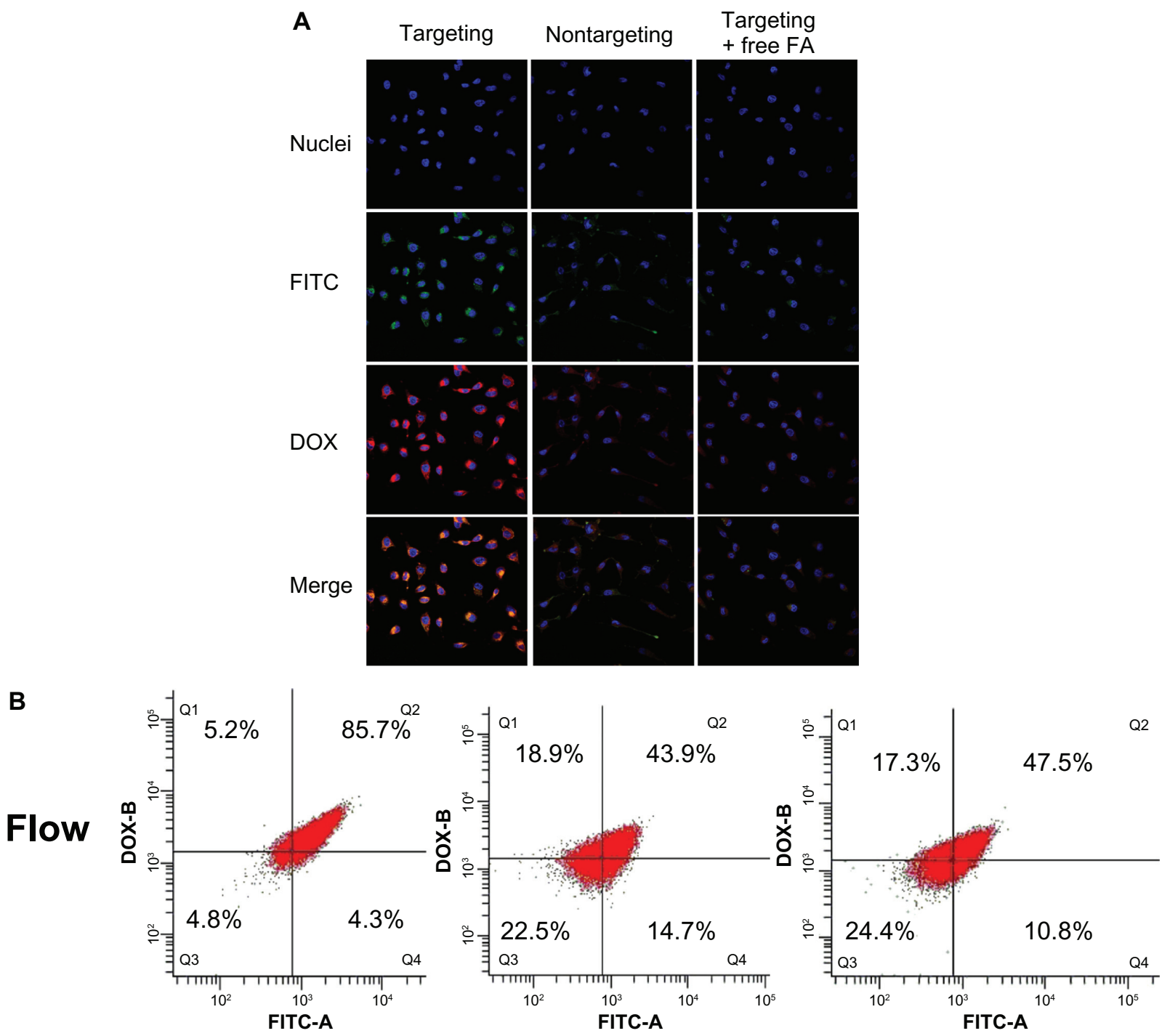

Figure 7 Four upper panels: laser confocal microscopic images of cells incubated with D-FPPP/FITC (targeting), D-NPPP/FITC (nontargeting), and D-FPPP/FITC in the presence of FA (I mg/L) (targeting + FA).

Notes: Bottom panel: flow cytometric measurement of DOX and/or FITC positive cells. Nuclei: stained blue with Hoechest 33342 (Aldrich); Red florescence: DOX; Green fluorescence: SCR-FITC. Incubation time: 4 hours. Dose: $50 \mathrm{nM}$ siRNA. N/P = 30. DOX loading contents: $4.56 \%$ in D-FPPP and 5. I4\% in D-NPPP. Q1: DOX florescent cells; Q2: DOX and FITC florescent cells; Q3: nonflorescent cells; Q4: FITC florescent cells.

Abbreviations: DOX, doxorubicin; FA, folate; FITC, fluorescein isothiocyanate; D-FPPP/FITC, DOX and FITC labeled siRNA loaded folate-poly(ethylene glycol)poly(ethylene imine)-poly(E-caprolactone) micelle; D-NPPP/FITC, DOX and FITC labeled siRNA loaded nontargeted poly(ethylene glycol)-poly(ethylene imine)poly (E-caprolactone) micelle.

Next, ELISA assay was used to investigate the effect of nanocomplexes on the expression of antiapoptotic protein Bcl-2 and proapoptotic protein Bax in skov-3 cells. As shown in Figure 9, treatment using the folate-targeted nanocomplexes resulted in the most significant downregulation of the antiapoptotic Bcl-2 protein, regardless of DOX codelivery (see D-FPPP/Bcl-2 vs B-FPPP/Bcl-2), which is consistent with the real time-PCR data. Conversely, D-FPPP/Bcl-2 treatment caused the most remarkable upregulation of the proapoptotic Bax protein. Decrease in Bcl-2 and/or increase in Bax expression has been previously reported to induce apoptosis in other cancer cells treated with doxorubicin and other agents, such as doxorubicin in hematopoietic cells, ${ }^{27}$ as well as the topoisomerase inhibitors camptothecin, etoposide, and amsacrine, ${ }^{28}$ and NF- $k \mathrm{~B}$ inhibitor $\mathrm{SN} 50^{29}$ in $\mathrm{Rb}$ cells. The above results indicate that co-delivery of Bcl-2 siRNA and DOX using our dual carrier has the potential to enhance apoptosis in skov-3 cells, which will be confirmed by the study on nanocomplex-induced cell apoptosis.

\section{Enhancement of apoptosis via codelivery of siRNA and DOX}

The number of TUNEL-positive cells (ie, cells with brown nuclei) was counted to obtain the percentage of apoptotic cells. 


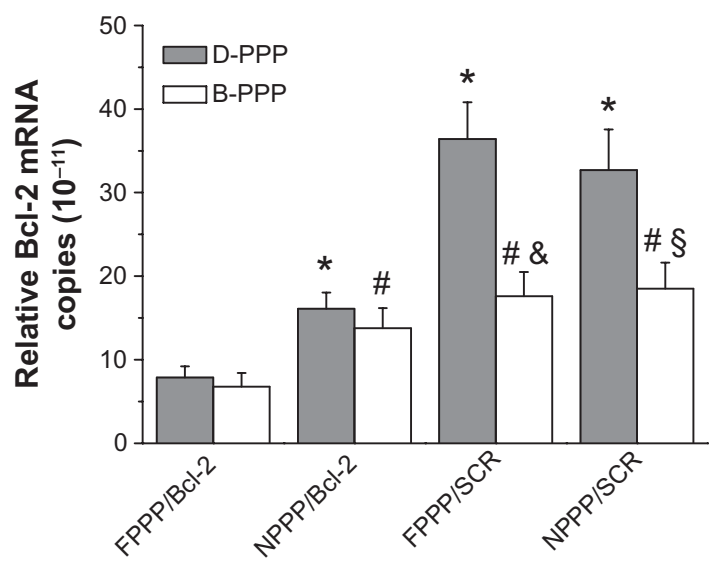

Figure 8 Efficacy of nanocomplexes in suppressing the Bcl-2 mRNA expression in skov-3 cells, as quantified by real-time PCR analysis $(n=3)$.

Notes: For the nanocomplex pairs shown under the $\mathrm{X}$-axis, the blank and grey bars show data for nanocomplexes delivering siRNA alone and nanocomplexes codelivering siRNA and DOX, respectively. Incubation time: 96 hours; N/P = 30; Dose: $25 \mathrm{nM}$ siRNA per well. ${ }^{*} P<0.05$, compared with D-FPPP/Bcl-2; ${ }^{*} P<0.05$, compared with B-FPPP/Bcl-2 group; \&P $<0.05$, compared with D-FPPP/SCR; $\S P<0.05$, compared with D-NPPP/SCR.

Abbreviations: DOX, doxorubicin; D-PPP, DOX loaded poly(ethylene glycol)poly(ethylene imine)-poly( $\varepsilon$-caprolactone) micelle; B-PPP, blank poly(ethylene glycol)-poly(ethylene imine)-poly( $\varepsilon$-caprolactone) micelle; FPPP/Bcl-2, Bcl-2 siRNA loaded folate-poly(ethylene glycol)-poly(ethylene imine)-poly( $\varepsilon$-caprolactone) micelle; NPPP/Bcl-2, Bcl-2 siRNA loaded nontargeted poly(ethylene glycol)poly(ethylene imine)-poly( $(\varepsilon$-caprolactone) micelle; FPPP/SCR, scrambled siRNA loaded folate-poly(ethylene glycol)-poly(ethylene imine)-poly(e-caprolactone) micelle; NPPP/SCR,scrambled siRNA loaded nontargeted poly(ethylene glycol)poly(ethylene imine)-poly( $\varepsilon$-caprolactone) micelle.

As shown in Figure 10, skov-3 cells incubated with various nanocomplexes showed significantly different apoptosis levels.

The highest apoptosis (77.5\%) was observed in cells incubated with folate-targeted nanocomplex containing both DOX and Bcl-2 siRNA (ie, D-FPPP/Bcl-2), which was even stronger than the total of the B-FPPP/Bcl-2 (10.8\%) and D-FPPP/SCR (50.2\%) effects, indicating the synergistic effect of codelivered DOX and Bcl-2 siRNA in inducing cell apoptosis. Next, we confirmed that the enhanced cell apoptosis was a synthetic outcome of the codelivered DOX and siRNA, by investigated the effect of nanocomplexes on the caspase- 3 activation, which is an important upstream factor leading to apoptosis, and thus, a good indicator of apoptosis in mammalian cells..$^{30} \mathrm{It}$ is known that caspase-3-like activity is increased through a protease cascade during early stage apoptosis. ${ }^{31}$ Consistent with the results of the TUNEL assay, D-FPPP/Bcl-2 treatment led to the most significant activation of caspase- 3 in skov-3 cells among the various nanocomplexes (Figure 11).

\section{DOX cytotoxicity enhanced by codelivered siRNA}

The antitumor effect of the combined treatment using siRNA and DOX codelivery strategy was evaluated by
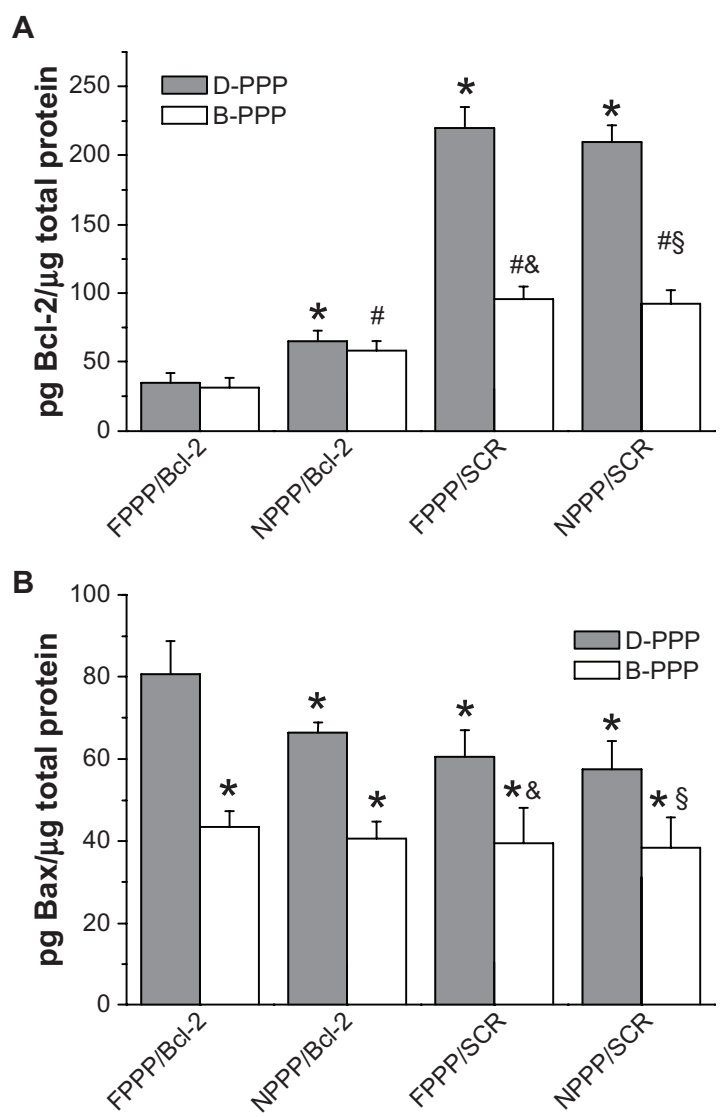

Figure 9 Protein expression levels of $(\mathbf{A}) \mathrm{Bcl}-2$ gene and $(\mathbf{B})$ Bax gene determined by ELISA $(n=6)$.

Notes: Incubation time: 96 hours; Dose: $50 \mathrm{nM}$ siRNA per well; N/P $=30$. Statistics in A: $* P<0.05$ compared with D-FPPP/Bcl-2; ${ }^{*} P<0.05$ compared with B-FPPP/ $\mathrm{Bcl}-2$; ${ }^{\&} \mathrm{P}<0.05$ compared with D-FPPP/SCR; $\$ P<0.05$ compared with D-NPPP/ SCR. Statistics in B: $* P<0.05$ compared with D-FPPP/Bcl-2; ${ }^{\&}<0.05$ compared with D-FPPP/SCR; ${ }^{\circledR} P<0.05$ compared with D-NPPP/SCR.

Abbreviations: DOX, doxorubicin; D-PPP, DOX loaded poly(ethylene glycol)poly(ethylene imine)-poly( $\varepsilon$-caprolactone) micelle; B-PPP, blank-poly(ethylene glycol)-poly(ethylene imine)-poly(E-caprolactone) micelle; FPPP/Bcl-2, Bcl-2 siRNA loaded folate-poly(ethylene glycol)-poly(ethylene imine)-poly( $\varepsilon$-caprolactone) micelle; NPPP/Bcl-2, Bcl-2 siRNA loaded nontargeted poly(ethylene glycol)poly(ethylene imine)-poly(E-caprolactone) micelle; FPPP/SCR, scrambled siRNA loaded folate-poly(ethylene glycol)-poly(ethylene imine)-poly( $\varepsilon$-caprolactone) micelle; NPPP/SCR, scrambled siRNA loaded nontargeted poly(ethylene glycol)poly(ethylene imine)-poly(E-caprolactone) micelle.

determining the percentage of viable cells in the presence of various nanocomplexes, using MTT Assay. As summarized in Figure 12, the cytotoxicity of the nanocarriers without loading DOX was fairly low, and was further lessened upon siRNA complexation. The viability of skov-3 cells incubated with B-FPPP/SCR and B-NPPP/SCR was above $90 \%$ at polymer concentrations up to $20 \mu \mathrm{g} / \mathrm{mL}$. When the cells were treated with DOX-loaded complexes, the cell viability decreased, along with increasing the concentration of DOX. Moreover, the combined treatment of DOX and Bcl-2 siRNA, mediated by the folate-targeted nanovector, yielded higher cytotoxicity than treatment with a single therapeutic agent or 


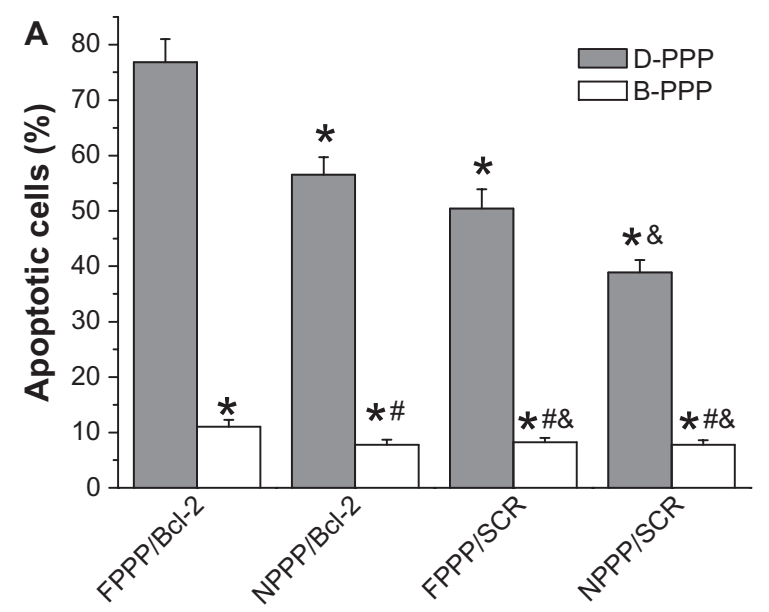

B

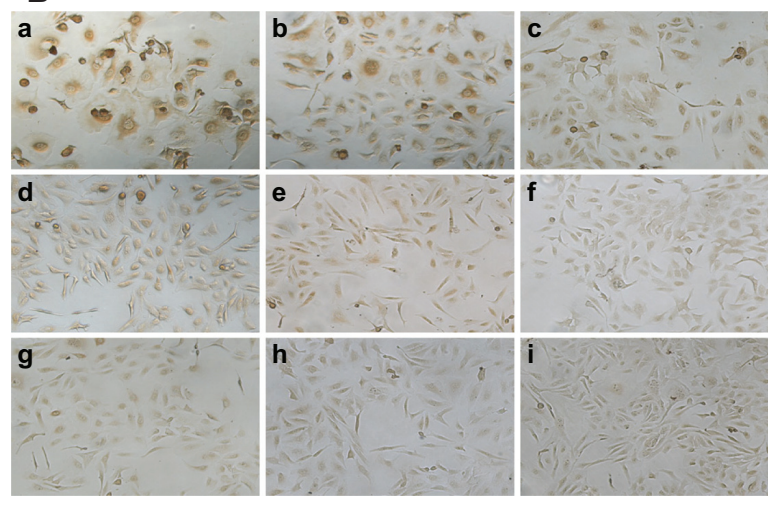

Figure 10 Detection of apoptotic skov-3 cells by TUNEL assay. (A) Percentage of apoptotic cells summarized from data of TUNEL assay $(n=6)$. (B) Images show cells incubated with: (a) D-FPPP/Bcl-2; (b) D-NPPP/Bcl-2; (c) D-FPPP/SCR; (d) D-NPPP/SCR; (e) B-FPPP/Bcl-2; (f) B-NPPP/Bcl-2; (g) B-FPPP/SCR; (h) B-NPPP/ SCR; (i) normal culture medium (control group).

Notes: Incubation time: 96 hours; N/P = 30; Dose: 50 nM siRNA per well. $* P<0.05$ compared with D-FPPP/Bcl-2; ${ }^{\#} P<0.05$ compared with B-FPPP/Bcl-2; ${ }^{\circledR} P<0.05$ compared with D-FPPP/SCR.

Abbreviations: DOX, doxorubicin; siRNA, small interference RNA; D-PPP, DOX loaded poly(ethylene glycol)-poly(ethylene imine)-poly(E-caprolactone) micelle; B-PPP, blank poly(ethylene glycol)-poly(ethylene imine)-poly( $\varepsilon$-caprolactone) micelle; FPPP/Bcl-2, Bcl-2 siRNA loaded folate-poly(ethylene glycol)-poly(ethylene imine)-poly( $\varepsilon$-caprolactone) micelle; NPPP/Bcl-2, Bcl-2 siRNA loaded nontargeted poly(ethylene glycol)-poly(ethylene imine)-poly( $\varepsilon$-caprolactone) micelle; FPPP/ SCR,scrambled siRNA loaded folate-poly(ethylene glycol)-poly(ethylene imine)poly( $\varepsilon$-caprolactone) micelle; NPPP/SCR, scrambled siRNA loaded nontargeted poly(ethylene glycol)-poly(ethylene imine)-poly(E-caprolactone) micelle.

treatment mediated by the nontargeting vector (Figure 12). For example, at $0.1 \mu \mathrm{M}$ DOX concentration, the MTT assay revealed $18.87 \%$ viability for cells treated with D-FPPP/Bcl2 , compared with more than $50 \%$ viability for cells incubated with other nanocomplexes.

\section{Discussion}

The combination of chemotherapy and genetic therapy is an emerging method for cancer treatment that has attracted great attention recently. A key point for its application is the development of codelivery vectors possessing not

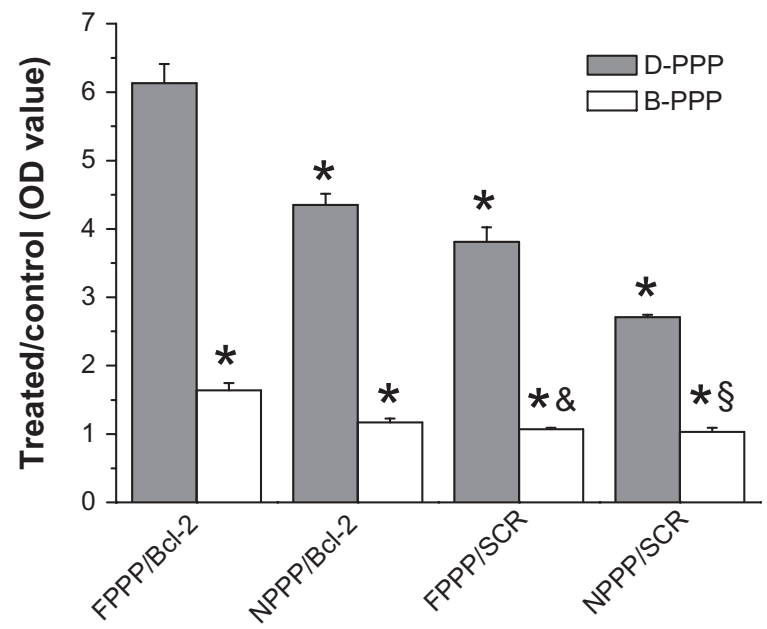

Figure II Activation of caspase-3 determined by Caspase-3 Colorimetric Assay Kit $(\mathrm{n}=6)$.

Notes: Incubation time: 96 hours; N/P $=30$; Dose: $50 \mathrm{nM}$ siRNA per well. $* P<0.05$ compared with D-FPPP/Bcl-2; ${ }^{*} P<0.05$ compared with D-FPPP/SCR; $\S P<0.05$ compared with D-NPPP/SCR.

Abbreviations: DOX, doxorubicin; siRNA,small interference RNA; D-PPP, DOX loaded poly(ethylene glycol)-poly(ethylene imine)-poly( $\varepsilon$-caprolactone) micelle; B-PPP, blank poly(ethylene glycol)-poly(ethylene imine)-poly( $\varepsilon$-caprolactone) micelle; FPPP/Bcl-2, Bcl-2 siRNA loaded folate-poly(ethylene glycol)-poly(ethylene imine)-poly( $\varepsilon$-caprolactone) micelle; NPPP/Bcl-2, Bcl-2 siRNA loaded nontargeted poly(ethylene glycol)-poly(ethylene imine)-poly(E-caprolactone) micelle; FPPP/ SCR, scrambled siRNA loaded folate-poly(ethylene glycol)-poly(ethylene imine)poly(E-caprolactone) micelle; NPPP/SCR, scrambled siRNA loaded nontargeted poly(ethylene glycol)-poly(ethylene imine)-poly( $\varepsilon$-caprolactone) micelle.

only high performance in dual transportation function, but low toxicity as well. In the present study, we synthesized a ternary block copolymer PEG-PEI-PCL, which in aqueous media formed cationic nanocarriers capable of encapsulating chemotherapeutic hydrophobic drugs and siRNA. This dual functional delivery vector demonstrated low cytotoxicity and, at the same time, high efficiency in codelivering DOX and siRNA into ovarian cancer cells. Compared to branched PEI25k, which showed high cytotoxicity, reaching $85 \%$ cell growth inhibition at $10 \mu \mathrm{g} / \mathrm{mL}$, PEG-PEI-PCL only caused $20 \%$ cell growth inhibition at the same concentration. Moreover, the cytotoxicity of the copolymer after complexing SCR was significantly lower than that of the SCR-complexed PEI, as well at the same N/P ration of 30 (Figure 12A). In addition to the low cytotoxicity of $1 \mathrm{PEI}$, an underlying cause for the low cytotoxicity of PEG-PEI-PCL is that PEG may form a water-soluble layer surrounding the nanoparticle, which can shield the positive charge and, consequently, reduce cytotoxicity. ${ }^{32}$

Based on the fact that skov-3 cells overexpress folate receptors, ${ }^{33,34}$ we employed folate as a targeting ligand to functionalize PEG-PEI-PCL, in hopes of improving its transfer efficacy for drug and siRNA. A cell uptake study 

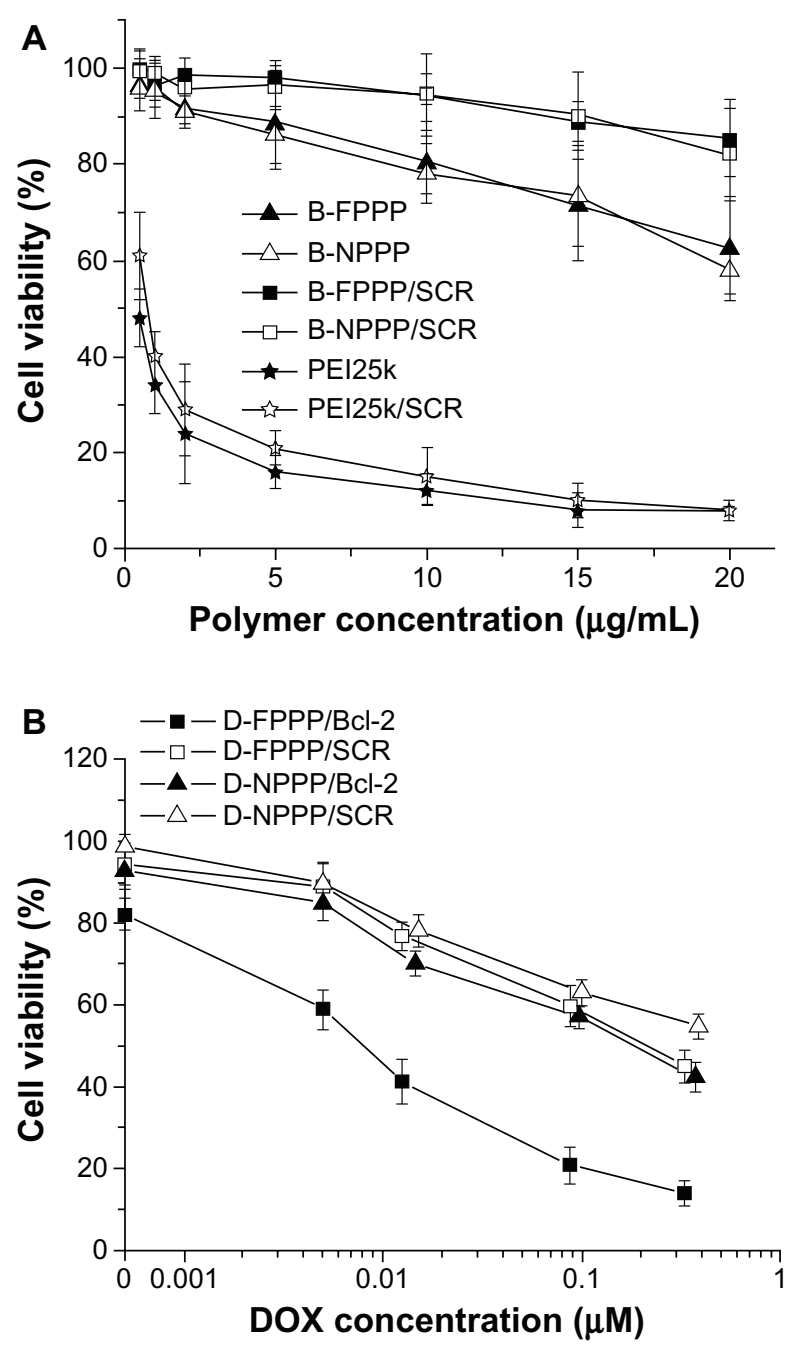

Figure 12 (A) Cell viability in the presence of polymers (PEI or blank copolymer micelles) and their SCR-complexed nanocomplexes at various polymer concentrations. (B) Viability of cells in the presence of nanocomplexes at various DOX concentrations.

Notes: Incubation time: 96 hours; N/P = 30 for all siRNA nanocomplexes; data are shown as mean $\pm S D(n=3)$.

Abbreviations:DOX, doxorubicin;siRNA,smallinterferenceRNA;B-FPPP, blankfolatepoly(ethylene glycol)-poly(ethylene imine)-poly( $\varepsilon$-caprolactone) micelle; B-NPPP, blanknontargeted poly(ethylene glycol)-poly(ethylene imine)-poly( $\varepsilon$-caprolactone) micelle; B-FPPP/SCR,scrambled siRNA-blank-folate-poly(ethylene glycol)-poly(ethylene imine)poly( $\varepsilon$-caprolactone) micelle; B-NPPP/SCR, scrambled siRNA-blank-nontargetingpoly(ethylene glycol)-poly(ethylene imine)-poly(E-caprolactone) micelle; PEI25k, scrambled siRNA complexed poly(ethylene imine) $25 \mathrm{kDa}$.

confirmed the feasibility of the strategy (Figure 7). The folate-targeted nanoparticles transported DOX and siRNA into the skov-3 cells more efficiently than the nontargeting nanoparticles, coinciding with our previous research results using folate to guide targeting delivery of nanoparticles. ${ }^{16}$ Real-time PCR and ELISA assays further confirmed that codelivery of siRNA and DOX using our folate-targeted nanocarrier can significantly improve the gene silencing effect of siRNA that targets the drug-resistant Bcl-2 gene. Although an increase in the expression of antiapoptotic Bcl-2 protein can be induced by DOX treatment in skov-3 cells, such upregulation can be significantly suppressed by the silencing effect of the codelivered Bcl-2 siRNA. MTT and TUNEL assays demonstrated the synergistic effect of siRNA and DOX codelivered by the folate-targeted nanocarrier in inducing apoptosis and death of skov-3 cells (Figures 10 and 12). That is, D-FPPP/Bcl-2 showed the best effect, both in inhibiting cell viability and in inducing cell apoptosis, even stronger than the total effect of B-FPPP/ Bcl-2 and D-FPPP/SCR.

It has been well documented that DOX induces cancer cell apoptosis via the mitochondrial pathway, which was found to depend on the expression of proapoptotic Bax gene as well. ${ }^{35-40}$ Bax expression can induce the mitochondrial membrane to emerge pores and reduce the mitochondrial potential, ultimately leading to the release of cytochrome c to the cytoplasm ${ }^{41}$ and activation of caspases. ${ }^{42}$ Previous studies ${ }^{43}$ showed that the expression of Bcl-2 acted upstream and prevented the above-mentioned effect of Bax. There were also reports ${ }^{44,45}$ that Bcl-2 and Bax can form heterodimerization, which plays a critical role in preventing Bax-mediated apoptosis. Not only was the DOX treatmentinduced upregulation of Bcl-2 expression in skov-3 cells significantly suppressed by Bcl-2 siRNA, but a significantly upregulated expression of the proapoptotic Bax gene also took place simultaneously, when the folate-targeted dualfunctional nanocarrier (D-FPPP) was employed for the codelivery of DOX and siRNA (Figure 9). Therefore, the most significant activation of caspase- 3 was achieved in the treated skov-3 cells overexpressing FA-receptors (Figure 11), leading to the highest levels of cell viability inhibition and apoptosis, as determined by the MTT and TUNEL assays, respectively.

\section{Conclusion}

In summary, we have prepared a safe and high-performance, dual-functional nanocarrier for the codelivery of Bcl-2 siRNA and DOX. It was confirmed that folate functionalization of the nanocarrier improved the delivery efficiency of both DOX and siRNA. Our results strongly demonstrated that DOX-induced cancer cell apoptosis relied on the high expression level of proapoptotic protein Bax; however, the simultaneous overexpression of Bcl-2 protein can prevent Bax-mediated cell apoptosis. Therefore, codelivery of Bcl-2 siRNA and DOX, using the folate-targeted, dualfunctional nanocarrier, can efficiently silence the Bcl-2 gene and, consequently, improve the sensitivity of the skov-3 cells to DOX treatment. 


\section{Acknowledgments}

This work was supported by the National Natural Science Foundation of China (50830107, 20974129, U1032002, 81070349, 81071167), The Natural Science Foundation (9351027501000003) and S\&T Programs (2009B030803003, 2010B031500011) of Guangdong Province, and the Guangzhou Scientific Project (2008Z1-D171).

\section{Disclosure}

The authors report no conflicts of interest in this work.

\section{References}

1. Jemal A, Siegel R, Ward E, Hao Y, Xu J, Thun MJ. Cancer statistics, 2009. CA Cancer J Clin. 2009;59(4):225-249.

2. Chauhan SC, Kumar D, Jaggi M. Mucins in ovarian cancer diagnosis and therapy. J Ovarian Res. 2009;2:21.

3. Armstrong DK. Relapsed ovarian cancer: challenges and management strategies for a chronic disease. Oncologist. 2002;7(Suppl 5):20-28.

4. Singal PK, Iliskovic N. Doxorubicin-induced cardiomyopathy. $N$ Engl J Med. 1998;339(13):900-905.

5. BuzdarAU, Marcus C, Smith TL, Blumenschein GR. Early and delayed clinical cardiotoxicity of doxorubicin. Cancer. 1985;55(12):2761-2765.

6. Yallapu MM, Jaggi M, Chauhan SC. Scope of nanotechnology in ovarian cancer therapeutics. J Ovarian Res. 2010;3:19.

7. Minotti G, Menna P, Salvatorelli E, Cairo G, Gianni L. Anthracyclines: molecular advances and pharmacologic developments in antitumor activity and cardiotoxicity. Pharmacol Rev. 2004;56(2):185-229.

8. Billingham ME, Mason JW, Bristow MR, Daniels JR. Anthracycline cardiomyopathy monitored by morphologic changes. Cancer Treat Rep. 1978;62(6):865-872.

9. Labialle S, Gayet L, Marthinet E, Rigal D, Baggetto LG. Transcriptional regulators of the human multidrug resistance 1 gene: recent views. Biochem Pharmacol. 2002;64(5-6):943-948.

10. Scatena CD, Stewart ZA, Mays D, et al. Mitotic phosphorylation of Bcl-2 during normal cell cycle progression and Taxol-induced growth arrest. J Biol Chem. 1998;273(46):30777-30784.

11. DantzigAH, Shepard RL, Cao J, et al. Reversal of P-glycoprotein-mediated multidrug resistance by a potent cyclopropyldibenzosuberane modulator, LY335979. Cancer Res. 1996;56(18):4171-4179.

12. Igney FH, Krammer PH. Death and anti-death: tumour resistance to apoptosis. Nat Rev Cancer. 2002;2(4):277-288.

13. Gross A. Mitochondrial carrier homolog 2: a clue to cracking the BCL-2 family riddle? J Bioenerg Biomembr. 2005;37(3):113-119.

14. Decaudin D, Geley S, Hirsch T, et al. Bcl-2 and Bcl-XL antagonize the mitochondrial dysfunction preceding nuclear apoptosis induced by chemotherapeutic agents. Cancer Res. 1997;57(1):62-67.

15. Lima RT, Martins LM, Guimarães JE, Sambade C, Vasconcelos MH. Specific downregulation of bcl-2 and xIAP by RNAi enhances the effects of chemotherapeutic agents in MCF-7 human breast cancer cells. Cancer Gene Ther. 2004;11(5):309-316.

16. Cao N, Cheng D, Zou S, Ai H, Gao J, Shuai X. The synergistic effect of hierarchical assemblies of siRNA and chemotherapeutic drugs co-delivered into hepatic cancer cells. Biomaterials. 2011;32(8):2222-2232.

17. Haley B, Frenkel E. Nanoparticles for drug delivery in cancer treatment. Urol Oncol. 2008;26(1):57-64.

18. Wang Y, Gao S, Ye WH, Yoon HS, Yang YY. Co-delivery of drugs and DNA from cationic core-shell nanoparticles self-assembled from a biodegradable copolymer. Nat Mater. 2006;5(10):791-796.

19. Zhu C, Jung S, Luo S, et al. Co-delivery of siRNA and paclitaxel into cancer cells by biodegradable cationic micelles based on PDMAEMA-PCL-PDMAEMA triblock copolymers. Biomaterials. 2010;31(8):2408-2416.
20. Qiu LY, Bae YH. Self-assembled polyethylenimine-graft-poly ( $\varepsilon$-caprolactone) micelles as potential dual carriers of genes and anticancer drugs. Biomaterials. 2007;28(28):4132-4142.

21. Cheng D, Cao N, Chen J, Yu X, Shuai X, Multifunctional nanocarrier mediated co-delivery of doxorubicin and siRNA for synergistic enhancement of glioma apoptosis in rat. Biomaterials. 2012;33(4):1170-1179.

22. Shuai XT, Merdan T, Unger F, Wittmar M, Kissel T. Novel biodegradable ternary copolymers $h y$-PEI- $g$-PCL- $b$-PEG: synthesis, characterization, and potential as efficient nonviral gene delivery vectors. Macromolecules. 2003;36(15):5751-5759.

23. Cammas S, Nagasaki Y, Kataoka K. Heterobifunctional poly(ethylene oxide): synthesis of $\alpha$-methoxy- $\omega$-amino and $\alpha$-hydroxy- $\omega$ amino PEOs with the same molecular weights. Bioconjug Chem. 1995;6(2):226-230.

24. Mukhopadhyay P, Bátkai S, Rajesh M, et al. Pharmacological inhibition of CB1 cannabinoid receptor protects against doxorubicin-induced cardiotoxicity. J Am Coll Cardiol. 2007;50(6):528-536.

25. Chen GH, Chen WJ, Wu Z, et al. MRI-visible polymeric vector bearing CD3 single chain antibody for gene delivery to T cells for immunosuppression. Biomaterials. 2009;30(10):1962-1970.

26. Wang DA, Narang AS, Kotb M, et al. Novel branched poly(ethylenimine)cholesterol water-soluble lipopolymers for gene delivery. Biomacromolecules. 2002;3(6):1197-1207.

27. Panaretakis T, Pokrovskaja K, Shoshan MC, Grandér D. Activation of $\mathrm{Bak}$, Bax, and $\mathrm{BH} 3$-only proteins in the apoptotic response to doxorubicin. J Biol Chem. 2002;277(46):44317-44326.

28. Giuliano M, Lauricella M, Vassallo E, Carabillo M, Vento R, Tesoriere G. Induction of apoptosis in human retinoblastoma cells by topoisomerase inhibitors. Invest Ophthalmol Vis Sci. 1998;39(8):1300-1311.

29. Poulaki V, Mitsiades CS, Joussen AM, Lappas A, Kirchhof B, Mitsiades N. Constitutive nuclear factor- $k \mathrm{~B}$ activity is crucial for human retinoblastoma cell viability. Am J Pathol. 2002;161(6):2229-2240.

30. Wang S, Konorev EA, Kotamraju S, Joseph J, Kalivendi S, Kalyanaraman B. Doxorubicin induces apoptosis in normal and tumor cells via distinctly different mechanisms. Intermediacy of $\mathrm{H}_{2} \mathrm{O}_{2}$ - and p53-dependent pathways. J Biol Chem. 2004;279(24):25535-25543.

31. Nicholson DW, Thornberry NA. Caspases: killer proteases. Trends Biochem Sci. 1997;22(8):299-306.

32. Petersen H, Fechner PM, Martin AL, et al. Polyethyleniminegraft-poly(ethylene glycol) copolymers: influence of copolymer block structure on DNA complexation and biological activities as gene delivery system. Bioconjug Chem. 2002;13(4):845-854.

33. Sudimack J, Lee RJ. Targeted drug delivery via the folate receptor. Adv Drug Deliv Rev. 2000;41(2):147-162.

34. Low PS, Henne WA, Doorneweerd DD. Discovery and development of folic-acid-based receptor targeting for imaging and therapy of cancer and inflammatory diseases. Acc Chem Res. 2008;41(1):120-129.

35. Clementi ME, Giardina B, Di Stasio E, MordenteA, Misiti F. Doxorubicinderived metabolites induce release of cytochrome $\mathrm{C}$ and inhibition of respiration on cardiac isolated mitochondria. Anticancer Res. 2003;23(3B):2445-2450.

36. Kalivendi SV, Kotamraju S, Zhao H, Joseph J, Kalyanaraman B. Doxorubicin-induced apoptosis is associated with increased transcription of endothelial nitric-oxide synthase. Effect of antiapoptotic antioxidants and calcium. J Biol Chem. 2001;276(50):47266-47276.

37. Gamen S, Anel A, Perez-Galan P, et al. Doxorubicin treatment activates a Z-VAD-sensitive caspase, which causes deltapsim loss, caspase-9 activity, and apoptosis in Jurkat cells. Exp Cell Res. 2000; 258(1):223-235.

38. Chen Y, Wan Y, Wang Y, Zhang H, Jiao Z. Anticancer efficacy enhancement and attenuation of side effects of doxorubicin with titanium dioxide nanoparticles. Int J Nanomedicine. 2011;6:2321-2326.

39. Panaretakis T, Laane E, Pokrovskaja K, et al. Doxorubicin requires the sequential activation of caspase-2, protein kinase Cdelta, and c-Jun NH2-terminal kinase to induce apoptosis. Mol Biol Cell. 2005;16(8):3821-3831. 
40. Decaudin D, Geley S, Hirsch T, et al. Bcl-2 and Bcl-XL antagonize the mitochondrial dysfunction preceding nuclear apoptosis induced by chemotherapeutic agents. Cancer Res. 1997;57(1):62-67.

41. Jurgensmeier JM, Xie Z, Deveraux Q, Ellerby L, Bredesen D, Reed JC. Bax directly induces release of cytochrome c from isolated mitochondria. Proc Natl Acad Sci U S A. 1998;95(9):4997-5002.

42. Li P, Nijhawan D, Budihardjo I, et al. Cytochrome c and dATPdependent formation of Apaf-1/caspase-9 complex initiates an apoptotic protease cascade. Cell. 1997;91(4):479-489.

43. Murphy KM, Ranganathan V, Farnsworth ML, Kavallaris M, Lock RB. Bcl-2 inhibits Bax translocation from cytosol to mitochondria during drug-induced apoptosis of human tumor cells. Cell Death Differ. 2000;7(1):102-111.
44. Oltvai ZN, Milliman CL, Korsmeyer SJ. Bcl-2 heterodimerizes in vivo with a conserved homolog, Bax, that accelerates programmed cell death. Cell. 1993;74(4):609-619.

45. Gross A, Jockel J, Wei MC, Korsmeyer SJ. Enforced dimerization of BAX results in its translocation, mitochondrial dysfunction and apoptosis. EMBO J. 1998;17(14):3878-3885.
International Journal of Nanomedicine

\section{Publish your work in this journal}

The International Journal of Nanomedicine is an international, peerreviewed journal focusing on the application of nanotechnology in diagnostics, therapeutics, and drug delivery systems throughout the biomedical field. This journal is indexed on PubMed Central, MedLine, CAS, SciSearch $®$, Current Contents ${ } /$ Clinical Medicine,

\section{Dovepress}

Journal Citation Reports/Science Edition, EMBase, Scopus and the Elsevier Bibliographic databases. The manuscript management system is completely online and includes a very quick and fair peer-review system, which is all easy to use. Visit http://www.dovepress.com/ testimonials.php to read real quotes from published authors.

Submit your manuscript here: http://www.dovepress.com/international-journal-of-nanomedicine-journal 